\title{
Discordant attitudes and beliefs about cancer clinical trial participation between physicians, research staff, and cancer patients
}

\author{
Grace C Hillyer $^{1,2}\left(\mathbb{D}\right.$, Melissa Beauchemin ${ }^{2,3,4}$, \\ Dawn L Hershman 1,2,5, Moshe Kelsen ${ }^{2}$ (D) Frances L Brogan², \\ Rossy Sandoval' ${ }^{2}$, Karen M Schmitt ${ }^{2,3}$, Andria Reyes ${ }^{2}$, \\ Mary Beth Terry ${ }^{1,2}$, Andrew B Lassman ${ }^{2,6}$ and Gary K Schwartz ${ }^{2,5}$
}

\begin{abstract}
Background/Aims: Essential to bringing innovative cancer treatments to patients is voluntary participation in clinical trials but approximately $8 \%$ of American cancer patients are enrolled onto a trial. We used a domain-oriented framework to assess barriers to cancer clinical trial enrollment.

Methods: Physicians (MD, DO, fellows, residents) and research staff (physician assistants, nurse practitioners, staff and research nurses, clinical assistants, and program coordinators) involved in clinical research at a comprehensive cancer center completed an online survey in 2017; adult cancer patients not currently enrolled in a trial were interviewed in 2018. To inform the construct of our physician/staff and patient surveys and to assess barriers to clinical trial enrollment, we first conducted in-depth interviews among 14 key informants representing medical, hematologic, gynecologic, neurologic, radiation oncology, as well as members of the clinical research team (one clinical research coordinator, one research nurse practitioner). Perceived structural, provider- and patient-level barriers to clinical trial enrollment were assessed. Differences in perceptions, attitudes, and beliefs toward clinical trial enrollment between (I) physicians and staff, (2) patients by ethnicity, and (3) physicians/staff and patients were examined.

Results: In total, 120 physicians/staff involved in clinical research (39.2\% physicians, $60.8 \%$ staff; $48.0 \%$ overall response rate) and 150 cancer patients completed surveys. Nearly three-quarters of physician/staff respondents reported difficulty in keeping track of the eligibility criteria for open studies but was more often cited by physicians than staff (84.4\% vs $64.3 \%, p=0.02$ ). Physicians more often reported lack of time to present clinical trial information than did staff $(p<0.001) ; 44.0 \%$ of staff versus $18.2 \%$ of physicians reported patient family interaction as a clinical trial enrollment barrier $(p=0.007)$. Hispanic patients more often stated they would join a trial, even if standard therapy was an option compared to non-Hispanic patients $(47.7 \%$ vs $20.8 \%, p=0.002)$. Comparing the beliefs and perceptions of physicians/ staff to those of patients, patients more often reported negative beliefs about clinical trial enrollment (e.g. being in a trial does not help patients personally, $32.9 \%$ vs $1.8 \%, p<0.001$ ) but less often felt they had no other options when agreeing
\end{abstract}

\footnotetext{
'Department of Epidemiology, Mailman School of Public Health of Columbia University, New York, NY, USA

${ }^{2}$ Herbert Irving Comprehensive Cancer Center of Columbia University, New York, NY, USA

${ }^{3}$ New York Presbyterian Hospital, New York, NY, USA

${ }^{4}$ Columbia University School of Nursing, New York, NY, USA

${ }^{5}$ Division of Hematology/Oncology, Columbia University Irving Medical Center, New York, NY, USA

${ }^{6}$ Department of Neurology, Columbia University Irving Medical Center, New York, NY, USA
}

Corresponding author:

Grace C Hillyer, Department of Epidemiology, Mailman School of Public Health, Columbia University, 722 West 168th Street, New York, NY I0032, USA.

Email: gah28@cumc.columbia.edu 
to join ( $38.1 \%$ vs $85.6 \%, p<0.001)$, and less often refused clinical trial enrollment due to lack of understanding $(9.1 \%$ vs $63.3 \%, p=0.001)$ than reported by physicians/staff.

Conclusion: Our findings indicate a wide gap between physician/staff and patient attitudes and beliefs about clinical trial enrollment and highlight the importance of focusing future initiatives to raise awareness of this incongruency. Reconciling these differences will require tailored education to reduce implicit biases and dispel misperceptions. Strategies to improve the quality of patient-provider communication and address infrastructure and resource issues are also needed to improve patient enrollment onto cancer clinical trials.

\section{Keywords}

Cancer clinical trials, clinical trials participation, patient/provider communication, health education

\section{Background}

Cancer clinical trials are a crucial step in advancing cancer treatment, and greater participation in clinical trials expedites these advances with potential to improve the lives of people with cancer. Most cancer patients, however, do not participate in a clinical trial. Recent estimates put overall clinical trial enrollment (CTE) in the United States at $8 \%$, ranging from $6.3 \%$ to $7.0 \%$ at community centers and $14.0 \%$ to $15.9 \%$ at academic centers. ${ }^{1-3}$ Although higher than the often cited participation rates of $3 \%-5 \%,{ }^{4-7}$ participation in clinical trials has changed little over the past few decades.

Barriers to cancer trial enrollment are complex and multifaceted. Several models to understand and address low clinical trial participation have been described, and all propose that barriers at multiple levels affect the phenomenon, specifically at the system, provider, and patient levels, ${ }^{1,3}$ as well as the interaction between each of these levels. ${ }^{8,9}$ Unger et al. proposed that CTE barriers can be categorized as structural (e.g. trial availability), clinical (e.g. patient eligibility), and attitudinal factors (both physician and patient). To address the structural barrier of trial availability, the National Cancer Institute funds cooperative groups to develop trials that are then available across the country through mechanisms that include the National Cancer Institute (NCI)-Community Oncology Research Program (NCORP) ${ }^{10}$ Exclusion of potentially eligible cancer patients due to rigid eligibility criteria, ${ }^{11,12}$ particularly individuals from underrepresented age, gender, and racial/ethnic groups for many clinical trials where representation is disproportionately low, ${ }^{13}$ is an issue that is currently under evaluation by the American Society of Clinical Oncology. ${ }^{14}$ For example, ethnic and racial minorities make up $38.7 \%$ of the US population ${ }^{15}$ but only make up $2 \%-16 \%$ of those enrolled in American cancer clinical trials, ${ }^{13,15,16}$ with $0.1 \%$ are American Indian, 2.2\% Hispanic, 3.3\% Asian, and 6.1\% Black/ African American. ${ }^{17}$ This, however, conflicts with reports indicating that racial and ethnic minority patients are as willing as whites to participate in health research and clinical trials. ${ }^{18,19}$ Much research has focused on addressing patient-related barriers as ultimately patients make the final decision whether or not to participate in a clinical trial. ${ }^{2,9,20,21}$ Interventions targeted toward patients alone, however, have variable effect; flexible and multifaceted strategies that address both patients and providers were found to be more effective. $^{22}$

Although, substantial work has been done to understand barriers to clinical trial participation, few studies have specifically targeted minority participation using a domain-oriented framework that includes an evaluation of provider and patient attitudes. Minorities represent $33 \%$ of all cancer patients seeking care at our large, urban NCI-Comprehensive Cancer Center and Minority Underserved NCI-Community Oncology Research Program (MU-NCORP) site, ${ }^{23} 21 \%$ of whom are Hispanic. However, the proportion of Hispanics in our catchment area is even higher at $27.4 \%$, ranging from $17.0 \%$ in Rockland County to $55.4 \%$ in the Bronx, New York. Our most recent efforts to increase minority CTE based on the Accrual to Clinical Trial framework ${ }^{24}$ included hiring a bilingual clinical trials navigator and conducting awareness campaigns to educate providers and patients. These efforts are expected to increase accrual to clinical trials, specifically among minority patients; however, minority CTE continues to be a challenge.

To identify actionable factors to increase CTE among of minority patients in general and Hispanic patients specifically, we examined the structural, and physician, and patient attitudinal barriers to cancer clinical trial participation among the providers and diverse groups of patients with cancer at our site. We also evaluated the knowledge and attitudes about clinical trials as well as perceptions about the barriers to CTE among key clinical personnel engaged in the conduct of cancer clinical trials and among a racially/ethnically diverse cancer patient population.

\section{Methods}

\section{Setting and subjects}

All procedures were conducted at a large urban Minority-Underserved NCORP site Columbia 
University Irving Medical Center (CUIMC). Physicians involved in clinical research and trial staff were identified from Cancer Center membership rosters. Cancer patient participants were recruited at medical, gynecologic, neurologic, and hematologic oncology clinics. Included were patients who were under the care of a cancer center clinical oncologist and were not currently enrolled in a clinical trial. Those not yet diagnosed with cancer or who were seeking second opinions regarding diagnosis were excluded. Participants were interviewed in the language of their preference (English or Spanish) by bilingual research team members. All procedures were approved by the CUIMC Institutional Review Board.

\section{Development of physician, staff, and patient surveys}

To inform the construct of our physician/staff and patient surveys and to assess barriers to CTE, we first conducted in-depth interviews among 14 key informants representing medical, hematologic, gynecologic, neurologic, radiation oncology, as well as members of the clinical research team (one clinical research coordinator, one research nurse practitioner). Key informants provided insight to successful strategies to increase accrual such as methods to identify potential participants, the importance of bilingual staff, and the development of a pervasive trials-friendly culture. Barriers identified included space and time constraints; need for increased coordinator support; desire for certain disease-specific trials; and perceived poor communication between oncology groups and subspecialties.

\section{Physicians and staff survey procedures}

The physician and staff surveys were conducted August through September 2017. An email invitation addressed from the Chief of the division of hematology/oncology (GS) was distributed to 250 physicians (MD, DO, fellows, and residents), clinical and research staff (physician assistants, nurse practitioners, staff and research nurses, clinical assistants, and program coordinators). A brief introduction to the study was included along with a unique link to a web-based informed consent and survey in Qualtrics. Consent and survey responses were uploaded via a secure Internet connection. Reminders were sent twice at 1-week intervals for nonrespondents.

The survey was developed based on a review of the literature and the key informant interviews. Prior to implementation, the feasibility of survey administration was tested among a sample of research coordinators and was found to be acceptable. The survey took approximately $8 \mathrm{~min}$ to complete. Structural barriers encountered in cancer $\mathrm{CTE}^{25}$ and personal positive and negative attitudes toward clinical trials ${ }^{25-27}$ were assessed. Perceived reasons why, from the participant's (clinical researcher/staff) perspective, cancer patients enroll in clinical trials ${ }^{28}$ and decline participation were determined. ${ }^{25-27}$ Reasons for study refusal were grouped as patient-related, psychosocial, logistic, and trial-related factors, and financial concerns based on categories identified in the literature.

\section{Patient survey procedures}

We used a convenience sampling strategy to approach adult cancer patients, aged 18 years and older in oncology clinic waiting rooms over a 6-month period. Patients who were under the care of a physician from the institution and who were not currently participating in a clinical trial were considered eligible to participate in this study. Surveys were conducted in the language preferred by the participant (English or Spanish) in a private area or examination room by bilingual research team members. Language in which the survey was conducted was recorded. Demographic information including age, gender, race/ethnicity, educational level, and marital status was collected. Health literacy was determined using a brief literacy screener, ${ }^{29}$ and awareness of clinical trials was evaluated by asking a single question, "Do you know what a clinical trial is?" with responses recorded as "Yes/No." Patient participants were asked if a clinical trial was ever offered to them and, if so, did they participate along with reasons for joining ${ }^{28}$ or declining. ${ }^{25-27}$ These questions, as well as questions regarding personal attitudes and beliefs toward clinical trials, mirrored questions asked of the physicians and staff. Finally, a series of five questions to ascertain the circumstances under which a patient would consider joining a clinical trial were posed to patient participants (e.g. "If you had tried all available standard treatment but it did not work, would you consider participating in a clinical trial for a new treatment?").

\section{Data analysis}

Descriptive analyses include frequency distributions, and mean, standard deviation, median, and range for continuous variables. Univariable tests of association using the chi-square test were performed to assess differences in categorical type questions and Student's $t$ test for continuous variables between physicians and clinical research staff and between Hispanic and nonHispanic cancer patients. Comparison between positive and negative clinical trial attitudes, and reasons for clinical trial participation and declination as perceived by physicians/staff versus cancer patients was conducted using chi-square test. $P$ values $<0.05$ were considered 
Table I. Structural barriers encountered by physicians and staff enrolling cancer patients onto clinical trials $(N=120)$, SeptemberNovember 2017.

\begin{tabular}{|c|c|c|c|c|}
\hline & $\begin{array}{l}\text { Total, } N=120 \\
n(\%)\end{array}$ & $\begin{array}{l}\text { Physicians, } n=47 \\
n(\%)\end{array}$ & $\begin{array}{l}\text { Staff } n=73 \\
n(\%)\end{array}$ & $P$ value \\
\hline \multicolumn{5}{|l|}{ Administrative } \\
\hline Paperwork is very complicated & $55(54.5)$ & $26(57.8)$ & $29(51.5)$ & 0.55 \\
\hline Lack of support staff to assist with enrollment & $47(45.6)$ & $24(52.2)$ & $23(40.4)$ & 0.23 \\
\hline Enrollment process is too time consuming & $48(49.0)$ & $26(56.5)$ & $22(42.3)$ & 0.16 \\
\hline Difficult to keep track of the eligibility criteria & $74(73.3)$ & $38(84.4)$ & $36(64.3)$ & 0.02 \\
\hline \multicolumn{5}{|l|}{ Patient-related } \\
\hline Patients frequently miss scheduled appointments & $35(35.7)$ & $14(32.6)$ & $21(38.2)$ & 0.56 \\
\hline Patients refuse placebo & $43(51.8)$ & $20(50.0)$ & $23(53.5)$ & 0.75 \\
\hline Interacting with the patient's family & $30(31.9)$ & $8(18.2)$ & $22(44.0)$ & 0.007 \\
\hline Minority patients are difficult to enroll & $28(30.8)$ & $12(28.6)$ & $16(32.7)$ & 0.67 \\
\hline \multicolumn{5}{|l|}{ Process-related } \\
\hline Very few eligible patients & 45 (46.9) & $22(5 \mid .2)$ & $23(43.4)$ & 0.45 \\
\hline Clinical trial protocols are too rigid & $36(35.0)$ & $16(34.8)$ & $20(35.1)$ & 0.97 \\
\hline Too difficult to match patients to trials & $24(28.2)$ & $13(31.7)$ & II $(25.0)$ & 0.49 \\
\hline $\begin{array}{l}\text { Lack of minority physicians to recruit } \\
\text { minority patients }\end{array}$ & $40(43.0)$ & $20(45.5)$ & $20(40.8)$ & 0.65 \\
\hline $\begin{array}{l}\text { Making time to discuss clinical trials with patients } \\
\text { during office visits }\end{array}$ & $47(50.5)$ & $31(67.4)$ & $16(34.0)$ & 0.001 \\
\hline $\begin{array}{l}\text { Translating documents into Spanish and other languages } \\
\text { is difficult and expensive }\end{array}$ & $42(44.7)$ & $21(48.8)$ & $2 I(4 I .2)$ & 0.46 \\
\hline $\begin{array}{l}\text { Communicating complex information to patients } \\
\text { is very difficult }\end{array}$ & $56(57.1)$ & $26(56.5)$ & $30(57.7)$ & 0.91 \\
\hline $\begin{array}{l}\text { No space to enroll and consent patients } \\
\text { Heavy clinical patient volume }\end{array}$ & $\begin{array}{l}30(30.6) \\
32(35.6)\end{array}$ & $\begin{array}{l}13(28.3) \\
20(44.4)\end{array}$ & $\begin{array}{l}17(32.7) \\
12(26.7)\end{array}$ & $\begin{array}{l}0.63 \\
0.08\end{array}$ \\
\hline
\end{tabular}

statistically significant, and all analyses were performed using IBM SPSS (version 24). ${ }^{30}$ All procedures were reviewed and approved by the Columbia University Medical Center Institutional Review Board.

\section{Results}

Surveys were distributed to 115 physicians and 135 clinical/research staff involved in the conduct of clinical trials. Of these, 161 responses were received (response rate $=64.4 \% ; 79 / 115=68.7 \%$ physicians and $82 /$ $135=60.7 \%$ clinical $/$ research staff). Duplicates and surveys with $\geqslant 50 \%$ missing data were removed, resulting in 120 surveys for analysis; 47 physicians (39.2\%) and $73(60.8 \%)$ clinical/research staff. A total of 150 cancer patients completed interviews; 98 (65.3\%) were non-Hispanic and 44 Hispanic (29.3\%).

\section{Physician and staff responses}

Nearly three-quarters $(n=74,73.3 \%)$ of respondents reported difficulty in keeping track of the eligibility criteria for open studies (Table 1). This was more often cited by physicians than staff $(84.4 \%$ vs $64.3 \%$, $p=0.02)$. Other barriers included complicated paperwork $(n=55,54.5 \%)$, difficulty in communicating complex information to patients $(n=56,57.1 \%)$, and patients refusing placebo $(n=43,51.8 \%)$. While overall only $31.9 \%$ of respondents found interacting with the patient's family to be a barrier to enrollment, staff twice as often as physicians $(44.0 \%$ vs $18.2 \%$, $p=0.007)$ reported this barrier. Conversely, physicians twice as often as research staff found making time to discuss clinical trials with patients during office visits to be difficult $(67.4 \%$ vs $34.0 \%, p=0.001)$.

\section{Patient responses}

The majority of cancer patient surveys were conducted in English (78.0\%); most participants were female $(59.3 \%)$, White $(61.3 \%)$, and non-Hispanic $(70.7 \%)$ (Table 2). Approximately one-quarter did not know what a clinical trial is, and only $21.3 \%$ had ever been invited to participate in a trial; of those, $66 \%$ joined the trial (14.0\% of all participants). When asked about circumstances under which they would "definitely" participate in a clinical trial, only $24 \%$ stated that would join today if asked. The highest proportion of participants $(72.7 \%)$ would "definitely" consider a clinical trial if they thought their cancer was incurable and the clinical trial offered a new treatment, followed by $66.0 \%$ who would "definitely" consider a trial of a new treatment if all available treatment had failed.

Hispanics were more likely to state that they did not know what a clinical trial is compared with nonHispanic patients $(52.3 \%$ vs $16.0 \%, p<0.001)$, but were as likely as non-Hispanics to report being invited to participate in a clinical trial $(11.4 \%$ vs $25.5 \%$, 
Table 2. Cancer patient clinical trials knowledge, attitudes, and beliefs by ethnicity $(N=150)$, May-September 2018 .

\begin{tabular}{|c|c|c|c|c|}
\hline & $\begin{array}{l}\text { Total }(N=150) \\
n(\%)\end{array}$ & $\begin{array}{l}\text { Non-Hispanic }(n=106) \\
n(\%)\end{array}$ & $\begin{array}{l}\text { Hispanic }(n=44) \\
n(\%)\end{array}$ & $p$ \\
\hline Survey language & & & & $<0.001$ \\
\hline English & $117(78.0)$ & $104(98.1)$ & $13(29.5)$ & \\
\hline Spanish & $33(22.0)$ & $2(1.9)$ & $31(70.5)$ & \\
\hline \multicolumn{5}{|l|}{ Demographics } \\
\hline Gender & & & & 0.97 \\
\hline Male & $61(40.7)$ & $43(40.6)$ & $18(40.9)$ & \\
\hline Female & $89(59.3)$ & $63(59.4)$ & $26(59.1)$ & \\
\hline \multicolumn{5}{|l|}{ Age } \\
\hline Mean (SD) & $61.5(14.1)$ & $61.7(14.7)$ & $61.0(12.5)$ & 0.79 \\
\hline Median & 64.0 & 63.5 & 64.0 & \\
\hline Range & $27-96$ & $27-96$ & $28-82$ & \\
\hline Hispanic/Latino & & & & - \\
\hline Yes & $44(29.3)$ & $0(0.0)$ & $44(100.0)$ & \\
\hline No & $106(70.7)$ & $106(100.0)$ & $0(0.0)$ & \\
\hline \multicolumn{5}{|l|}{ Race } \\
\hline African American/Afro & $20(13.3)$ & $13(12.3)$ & $7(15.9)$ & 0.63 \\
\hline \multicolumn{5}{|l|}{ Caribbean/African/Black } \\
\hline $\begin{array}{l}\text { American Indian/Alaskan } \\
\text { Native }\end{array}$ & $0(0.0)$ & $0(0.0)$ & $0(0.0)$ & - \\
\hline Asian/Pacific Islander & $8(5.3)$ & $8(7.5)$ & $0(0.0)$ & 0.11 \\
\hline White & $92(61.3)$ & $82(77.4)$ & $10(22.7)$ & $<0.001$ \\
\hline Mixed race & $25(16.7)$ & $3(2.8)$ & $22(50.0)$ & $<0.001$ \\
\hline Other & $6(4.0)$ & I (0.9) & $5(11.4)$ & 0.009 \\
\hline Education & & & & $<0.001$ \\
\hline No formal education & $0(0.0)$ & $0(0.0)$ & $0(0.0)$ & \\
\hline Grade I-8 & $16(10.7)$ & $3(2.8)$ & $13(29.5)$ & \\
\hline Grade $9-12$ & $34(22.7)$ & $16(15.1)$ & $16(40.9)$ & \\
\hline Some college & $22(14.7)$ & $14(13.2)$ & $8(18.2)$ & \\
\hline College & $32(21.3)$ & $28(26.4)$ & $4(9.1)$ & \\
\hline Graduate degree & $46(30.7)$ & $45(42.5)$ & I (2.3) & \\
\hline Marital status & & & & 0.56 \\
\hline Married/living as married & $89(59.3)$ & $65(61.3)$ & $24(54.5)$ & \\
\hline Single & $34(22.7)$ & $25(23.6)$ & $9(20.5)$ & \\
\hline Divorced/separated & $18(12.0)$ & $\mathrm{II}(10.4)$ & $7(15.9)$ & \\
\hline Widowed & $9(6.0)$ & $5(4.7)$ & $4(9.1)$ & \\
\hline \multicolumn{5}{|l|}{ Health literacy } \\
\hline \multicolumn{5}{|l|}{ information from your physician } \\
\hline Never & $\mathrm{I}(0.7)$ & I (0.9) & $0(0.0)$ & \\
\hline Almost never & $0(0.0)$ & $0(0.0)$ & $0(0.0)$ & \\
\hline Sometimes & $37(24.7)$ & $24(22.6)$ & $13(29.5)$ & \\
\hline All the time & $112(74.7)$ & $81(76.4)$ & $31(70.5)$ & \\
\hline $\begin{array}{l}\text { How often do you need help } \\
\text { with instructions and }\end{array}$ & & & & $<0.001$ \\
\hline \multicolumn{5}{|l|}{$\begin{array}{l}\text { information from your physician } \\
\text { or pharmacy }\end{array}$} \\
\hline Never & $77(51.7)$ & $64(61.0)$ & $13(29.5)$ & \\
\hline Almost never & $25(16.8)$ & $21(20.0)$ & $4(9.1)$ & \\
\hline Sometimes & $37(24.8)$ & $17(16.2)$ & $20(45.5)$ & \\
\hline All the time & $10(6.7)$ & $3(2.9)$ & $7(15.9)$ & \\
\hline \multicolumn{5}{|c|}{ Clinical trials knowledge and participation } \\
\hline Know what a clinical trial is & & & & $<0.001$ \\
\hline Yes & $110(73.3)$ & $89(84.0)$ & $21(47.7)$ & \\
\hline No & $40(26.7)$ & $17(16.0)$ & $23(52.3)$ & \\
\hline \multicolumn{5}{|l|}{$\begin{array}{l}\text { Ever invited to participate in a } \\
\text { clinical trial }\end{array}$} \\
\hline Yes & $32(21.3)$ & $27(25.5)$ & $5(\mid 1.4)$ & 0.055 \\
\hline No & $118(78.7)$ & $79(74.5)$ & $39(88.6)$ & \\
\hline Join the trial & & & & 0.46 \\
\hline Yes & $21(14.0)$ & $17(63.0)$ & $4(80.0)$ & \\
\hline No & $11(7.3)$ & $10(37.0)$ & I (20.0) & \\
\hline
\end{tabular}


Table 2. Continued

\begin{tabular}{|c|c|c|c|c|}
\hline & $\begin{array}{l}\text { Total }(N=150) \\
n(\%)\end{array}$ & $\begin{array}{l}\text { Non-Hispanic }(n=106) \\
n(\%)\end{array}$ & $\begin{array}{l}\text { Hispanic }(n=44) \\
n(\%)\end{array}$ & $p$ \\
\hline $\begin{array}{l}\text { Circumstances under which participc } \\
\text { If you were asked to participate } \\
\text { in a CT today, would you } \\
\text { participate }\end{array}$ & puld be considered & & & 0.05 \\
\hline Yes, I definitely would & $36(24.0)$ & $20(18.9)$ & $16(36.4)$ & \\
\hline I might, not sure, it depends & $97(64.7)$ & $75(70.8)$ & $22(50.0)$ & \\
\hline No, I definitely would not & $17(11.3)$ & II (I0.4) & $6(13.6)^{\prime}$ & \\
\hline $\begin{array}{l}\text { If you tried all available standard } \\
\text { treatment but it did not work, } \\
\text { would you consider participating } \\
\text { in a CT for a new treatment }\end{array}$ & & & & 0.56 \\
\hline Yes, I definitely would & $99(66.0)$ & 72 (67.9) & $27(6 \mid .4)$ & \\
\hline I might, not sure, it depends & $47(31.3)$ & $32(30.2)$ & $15(34.1)$ & \\
\hline No, I definitely would not & $4(2.7)$ & 2 (1.9) & $2(4.5)$ & \\
\hline $\begin{array}{l}\text { If you thought your cancer was } \\
\text { incurable, would you consider } \\
\text { participating in a CT for a new } \\
\text { treatment }\end{array}$ & & & & 0.12 \\
\hline Yes, I definitely would & $109(72.7)$ & $78(73.6)$ & $31(70.5)$ & \\
\hline I might, not sure, it depends & $35(23.3)^{\prime}$ & $26(24.5)$ & $9(20.5)$ & \\
\hline No, I definitely would not & $6(4.0)$ & 2 (1.9) & $4(9.1)$ & \\
\hline $\begin{array}{l}\text { If you thought your cancer could } \\
\text { be cured with standard } \\
\text { treatment, would you consider } \\
\text { participating in a CT of a new } \\
\text { treatment that may or may not } \\
\text { be better }\end{array}$ & & & & 0.002 \\
\hline Yes, I definitely would & $43(28.7)$ & $22(20.8)$ & $21(47.7)$ & \\
\hline I might, not sure, it depends & $78(52.0)$ & $64(60.4)$ & $14(31.8)$ & \\
\hline No, I definitely would not & $29(19.3)$ & $20(18.9)$ & $9(20.5)$ & \\
\hline $\begin{array}{l}\text { If you were offered participation } \\
\text { in a CT and there was an equal } \\
\text { chance you would either receive } \\
\text { standard treatment or a new } \\
\text { treatment, would you consider } \\
\text { participating in that CT }\end{array}$ & & & & 0.003 \\
\hline Yes, I definitely would & $48(32.0)$ & $25(23.6)$ & $23(52.3)$ & \\
\hline I might, not sure, it depends & $85(56.7)$ & $67(63.2)$ & $18(40.9)$ & \\
\hline No, I definitely would not & $17(11.3)$ & $14(13.2)$ & $3(6.8)$ & \\
\hline
\end{tabular}

SD: standard deviation; CT: clinical trial.

$p=0.055)$. However, when asked if they would participate in a clinical trial today if asked, $36.4 \%$ of Hispanic patients versus $18.9 \%$ non-Hispanic patients responded they would $(p=0.05)$ and twice as often responded "I definitely would" to joining a clinical if they thought their cancer could be cured with standard treatment but were offered a new treatment that may or may not better $(47.7 \%$ vs $20.8 \%, p=0.002)$ and if there was an equal chance of receiving either the standard treatment or the experimental treatment in a trial $(52.3 \%$ vs $23.6 \%, p=0.003)$ than non-Hispanic patients.

Few physicians and staff $(20.7 \%)$ agreed that clinical trials absolutely provide the best treatment available, and less than half $(43.9 \%)$ believed that the benefits of clinical trial participation outweighed any risks or harms. However, $57.0 \%$ felt that being in a clinical trial helps a patient be more in control of their disease and treatment (Table 3). One quarter of physicians and staff believed that patients enroll in clinical trials as a last resort. Researchers and staff perceived the most common reasons for patients to enroll in trials were to get better treatment $(93.9 \%)$, to get the newest treatment available $(92.2 \%)$, and because the patient had no better options $(85.6 \%)$. The most frequently cited reasons for declining a trial perceived by researchers and staff were concern about randomization or getting a placebo $(70.8 \%)$, followed by mistrust of the medical system, science, or researchers $(69.2 \%)$.

\section{Comparison of results among physicians, staff, and patients}

Comparison of the perceptions of the physicians and staff to patient attitudes showed that more often, 
Table 3. Comparison of clinical trial attitudes and reasons for participation or declination of clinical trial offers as perceived by physicians and staff and reported by cancer patients.

\begin{tabular}{|c|c|c|c|}
\hline & Physician/staff, $N=120$ & Patient, $N=150$ & $P$ value \\
\hline \multicolumn{4}{|l|}{ Clinical trial attitudes } \\
\hline Positive attitudes & $n(\%)$ & $n(\%)$ & \\
\hline $\begin{array}{l}\text { Being part of a clinical trial helps patients be more in } \\
\text { control of their disease and treatment }\end{array}$ & $65(57.0)$ & $104(69.3)$ & 0.04 \\
\hline $\begin{array}{l}\text { A clinical trial absolutely provides the best treatment } \\
\text { available }\end{array}$ & $24(20.7)$ & $90(60.0)$ & $<0.001$ \\
\hline $\begin{array}{l}\text { The benefits to patients of being in a clinical trial } \\
\text { outweigh any risks or harms }\end{array}$ & $50(43.9)$ & $85(57.0)$ & 0.03 \\
\hline $\begin{array}{l}\text { Clinical trials are important to the advancement of } \\
\text { medical science and clinical cancer care }\end{array}$ & II 5 (99.1) & | 48 (98.7) & 0.72 \\
\hline \multicolumn{4}{|l|}{ Negative attitudes } \\
\hline $\begin{array}{l}\text { Clinical trials are only offered to people whose } \\
\text { disease is hopeless }\end{array}$ & $10(8.7)$ & $41(27.3)$ & $<0.001$ \\
\hline $\begin{array}{l}\text { Being in a clinical trial does not help patients } \\
\text { personally }\end{array}$ & $2(1.8)$ & $49(32.9)$ & $<0.001$ \\
\hline $\begin{array}{l}\text { Patients who enroll in a clinical trial are gambling } \\
\text { with their life }\end{array}$ & $13(11.3)$ & $31(20.8)$ & 0.04 \\
\hline Doctors only offer clinical trials as a last resort & $14(12.2)$ & $35(23.5)$ & 0.019 \\
\hline Patients enroll in clinical trials as a last resort & $29(25.4)$ & $36(24.0)$ & 0.79 \\
\hline $\begin{array}{l}\text { Clinical trials are only good for the doctors, not for } \\
\text { the patients }\end{array}$ & $5(4.3)$ & $20(13.4)$ & 0.013 \\
\hline Reasons to participate in a clinical trial & & $n=21$ & \\
\hline To get better treatment & $108(93.9)$ & $20(95.2)$ & 1.00 \\
\hline Help people in the future & $92(80.0)$ & $18(85.7)$ & 0.76 \\
\hline To get newest treatment available & $107(92.2)$ & $19(90.5)$ & 0.68 \\
\hline Doctor recommended it & $100(84.0)$ & $19(90.5)$ & 0.74 \\
\hline Family wanted it & $56(50.0)$ & $7(33.3)$ & 0.07 \\
\hline Wanted a better chance at a cure & $94(80.3)$ & $20(95.2)$ & 0.12 \\
\hline Had no better options & $101(85.6)$ & $8(38.1)$ & $<0.001$ \\
\hline Reasons to decline participation in a clinical trial & & $n=11$ & \\
\hline \multicolumn{4}{|l|}{ Patient-related factors } \\
\hline Language/cultural barriers & $69(57.5)$ & $3(27.3)$ & 0.052 \\
\hline Religious reasons & $27(22.5)$ & $0(0.0)$ & 0.021 \\
\hline Lack of understanding about research trials & $76(63.3)$ & $1(9.1)$ & 0.001 \\
\hline Lack of interest in clinical trials & $41(34.2)$ & $4(40.0)$ & 0.71 \\
\hline \multicolumn{4}{|l|}{ Psychosocial factors } \\
\hline Mistrust of the medical system/science/researchers & $83(69.2)$ & $4(36.4)$ & 0.043 \\
\hline Feeling physically or emotionally Overwhelmed & $77(64.2)$ & $2(18.2)$ & 0.003 \\
\hline \multicolumn{4}{|l|}{ Logistic factors } \\
\hline Inconvenience & $7 \mid(59.2)$ & $3(27.3)$ & 0.04 \\
\hline Lack of transportation & $54(45.0)$ & $4(36.4)$ & 0.75 \\
\hline Family/personal responsibilities & $43(35.8)$ & $2(18.2)$ & 0.33 \\
\hline \multicolumn{4}{|l|}{ Trial-related factors } \\
\hline Invasive procedures & $50(4 I .7)$ & I (9.1) & 0.02 \\
\hline Concerns about toxicity & $72(60.0)$ & $2(18.2)$ & 0.006 \\
\hline Concerns about randomization or getting a placebo & $85(70.8)$ & $3(27.3)$ & 0.005 \\
\hline Preference for a proven treatment & $69(57.5)$ & $5(45.5)$ & 0.53 \\
\hline \multicolumn{4}{|l|}{ Financial concerns } \\
\hline Lack of insurance coverage & $35(29.2)$ & I (9.1) & 0.29 \\
\hline Additional out-of-pocket costs & $44(36.7)$ & $2(18.2)$ & 0.33 \\
\hline
\end{tabular}

patients endorsed a positive attitude about trial involvement, differing significantly from the views of the physicians and staff (Table 3). Patients more often agreed that the benefits of participation outweigh the risks or harms $(57.0 \%$ vs $43.9 \%, p=0.03)$. In addition, patients also more frequently reported negative attitudes toward clinical trials, many of which diverged significantly from the perceptions of physicians and staff. Patients more often than researchers believed that clinical trials are only offered to people whose disease is hopeless $(27.3 \%$ vs $8.7 \%, p<0.001)$, that being in a clinical trial does not help patients personally $(32.9 \%$ vs $1.8 \%, p<0.001)$, that enrolling in a clinical trial is gambling with their life $(20.8 \%$ vs $11.3 \%, p=0.04)$, 
and that clinical trials are offered as a last resort $(23.5 \%$ vs $12.2 \%, p 0.019)$.

Of patients offered a clinical trial and who agreed to participate $(n=21)$, opinions differed from those of the physicians and staff with $38.1 \%$ of patients who stated that having no better options was a consideration when making their decision to join compared to $85.6 \%$ of physicians who believed this was an important consideration for patients $(p<0.001)$. Among patients who were offered participation in a clinical trial but declined $(n=11)$, most frequent reasons for this choice were preference for a proven treatment $(45.5 \%)$, lack of interest $(40.0 \%)$. Reasons for declining participation cited by patients also varied significantly from those perceived by physicians and staff. For example, physicians/staff more often believed that patients decline clinical trial participation because of language and cultural barriers $(57.5 \%$ vs $27.3 \%$, $p<0.001$ ), lack of understanding about clinical trials $(63.3 \%$ vs $9.1 \%, p=0.001)$, and mistrust of the medical system $(69.2 \%$ vs $36.4 \%, p=0.043)$ compared to patient report. Patients also less often reported declining participation because of invasive procedures $(9.1 \%$ vs $41.7 \%, p=0.02)$, concerns about toxicity $(18.2 \%$ vs $60.0 \%, p=0.006$ ), and reluctance to be randomized or to receive a placebo $(27.3 \%$ vs $70.8 \%, p=0.005)$.

\section{Discussion}

Our findings demonstrate barriers to trial participation are frequent at the structural, provider, and patient levels. In addition, we found significant differences in perceived patient barriers to trial enrollment between research physicians and their staff; differences in barriers, attitudes, and beliefs between Hispanic and nonHispanic patients; and, most importantly, differences between what research physicians and staff believe are barriers for patients and what patients report as barriers.

The process of enrolling a cancer patient onto a clinical trial is multifaceted with the potential for breakdown at several key junctures along the way. Typically, patients newly diagnosed with cancer visit a cancer clinic and, depending on site infrastructure and protocols, are evaluated for trial eligibility. Assessment of eligibility, however, is contingent upon the availability of trials for the particular histology or stage of a patient's cancer. ${ }^{3}$ In a recent systematic review and meta-analysis of multi-level clinical trials barriers, Unger et al. reported that structural barriers are perhaps the greatest of barriers to trial participation; clinical trials were not available for $55.6 \%$ of cancer patients, and another $2.15 \%$ were ineligible for trials that were available. ${ }^{3}$ The structural barriers identified in our study that included difficulty in keeping track of eligibility criteria and carving out time during a visit to discuss trials and enrollment further complicate the first crucial step in the process of enrolling patients to clinical trials.

Once assessed as eligible for an available trial, the physician may or may not choose to discuss and offer trial enrollment to the patient. Physician bias and its impact on the decision whether or not offer a given patient a clinical trial has not been fully investigated. One example is a study conducted by Kornblith et al. that examined physician perceptions of barriers to clinical trials among elderly breast cancer patients. Physicians reported reluctance to enroll elderly patients due to comorbid conditions not excluded by trial protocol; that elderly patients would not fully understand trial procedures and would therefore likely be noncompliant; and that older patients may experience greater toxicity. ${ }^{31}$ Others have similarly reported how conscious and unconscious implicit physician bias against a patient's age and comorbidities as well as bias against members of minority groups and perceptions of patient mistrust of researchers. ${ }^{17}$ These biases sometimes result in spontaneous and reflexive decisions about the candidacy of a patient for a trial, influence patient-provider interactions, and lead to foregoing clinical trial options during discussions about treatment thus limiting offers of enrollment. ${ }^{17,32,33}$ Physician bias may also contribute to poor accrual to trials and early trial closure in addition to the lost opportunity to provide new treatments and better ancillary patient care. ${ }^{3,17}$

Only at the end of this process of negotiating structural and provider-level barriers does the patient's decision to participate enter the equation. Patients in our study more frequently endorsed negative attitudes about clinical trials, such as only being offered to those whose disease is hopeless, not helping patients personally, participation is gambling with one's life, and only being good for the doctor, not the patient. Consistent with prior literature, a significant number of patients cited a preference for standard treatment or a lack of interest in participating in clinical research as a reason for declining. ${ }^{34}$ Furthermore, our results demonstrate a significant difference in clinical trial knowledge and attitudes by ethnicity, with Hispanics reporting less awareness about clinical trials which is consistent with previously literature reporting lower participation in clinical trials in racial and ethnic minority groups. ${ }^{13}$ We also found that, despite less awareness of clinical trials and greater reported negative attitudes toward trials, Hispanic patients were more willing to consider a trial than their non-Hispanic counterparts were. When posed hypothetical conditions under which a patient might consider clinical trial participation, only a small proportion of patients overall stated that they definitely 
would not participate with Hispanics twice as often stating they would definitely participate. These findings are aligned with those of Comis et al. who reported that most Americans hold favorable views of clinical trial participation. ${ }^{19}$

Discordance between what physicians and research staff perceive as barriers and what patients state has not been previously reported. In our study, physicians and research staff often over- and under-estimated the importance of patient-reported barriers and highlight the ongoing communication that is needed between the provider/staff and patient. A study by Albrecht et al. of videotaped outpatient interactions between oncologists and patients and their family, when present, at two comprehensive cancer centers found that clinical trial participation was only offered to $20 \%$ of participants previously determined to be eligible for a trial, but when offered, $75 \%$ of these eligible patients assented. Greater shared conversation control with the physician was significantly related to the patient's decision to enroll highlighting the importance of content and relational communication between physicians and patients, provider-patient alliance building, and supportive dialogue in a full, clear, and open discussion of clinical trial participation. ${ }^{35}$

Our study had some strengths worth highlighting. First, we developed the survey from key informant interviews which revealed key structural and providerrelated topics that we included in our quantitative survey. This participatory research process ensured that we were asking relevant questions related to the topic. However, we did not include a patient representative in the development of our survey; this would have strengthened our study further. This is a single site, observational study conducted at a large urban Minority-Underserved NCORP site within an NCIdesignated comprehensive cancer center in New York City, which may limit generalizability of our findings to other geographic areas and patient populations. A major strength of this study is the unique assessment of the knowledge, attitudes, and beliefs of physicians and staff in parallel with those of patients. This allows us to have greater insight into the individual groups, but also to better develop tailored interventions within appropriate groups. Tailored, multi-level interventions have been cited as the most successful to reduce barriers to CTE, and the level of granularity and comparison that our data provides will support future initiatives.

\section{Conclusion}

Our study highlights the knowledge, attitudes, and beliefs about CTE from provider, staff, and patient perspectives and support previously defined barriers to clinical trial participation, specifically between Hispanic and non-Hispanic groups. These data also provide new information about the gaps between provider-/staffand patient-perceived barriers. Specifically, to our knowledge, this is the first published comprehensive assessment across physicians, staff, and patients to understand differences in perceptions about CTE barriers. Attitudes can be defined as a "learned tendency to evaluate things in a certain way" that are informed by personal experience, social norms, conditioning, and observation. ${ }^{36}$ Differences in attitudes between providers and patients are important to understand in order to focus future initiatives to raise awareness about incongruency between each group and reduce implicit biases. One possible strategy to address discordant provider/patient attitudes could be to incorporate these same factors that lead to the development of attitudes into educational interventions to effect attitude change. For example, enhancing personal CTE experiences for patients and providers through improved communication and streamlined workflow or promoting the enrollment of racial and ethnic minorities onto clinical trials as an institution-wide desired social norm. Clear, transparent communication between providers, staff, and patients about clinical trials should also be emphasized, as this will help to reduce inconsistencies across provider/patient continuum and in addition, help to reduce medical mistrust. ${ }^{22}$ Other strategies such as educating patients about clinical trials prior to their first oncology visit, ${ }^{37}$ engaging the community, diversifying the clinical and research staff to be more representative of the community, and providing education to the community and providers/staff may also help to reduce these barriers. 22

\section{Declaration of conflicting interests}

The author(s) declared no potential conflicts of interest with respect to the research, authorship, and/or publication of this article. Outside the submitted work, ABL declares personal compensation in the last 3 years from Karyopharm, Abbott Molecular, QED Therapeutics, Forma, Bayer, Northwest Biotherapeutics, AbbVie, Agios, Orbus, Bioclinica as an expert blinded independent reviewer of clinical and imaging data for a BMS-sponsored trial, Celgene, and Novocure.

\section{Funding}

The author(s) disclosed receipt of the following financial support for the research, authorship, and/or publication of this article: This study was supported in part by a National Cancer Institute Minority/Underserved Community Oncology Research Program (MU/NCORP), UM1 CA189960 and Cancer Center Support Grant P30CA013696.

\section{ORCID iDs}

Grace Clarke Hillyer (D) https://orcid.org/0000-0003-0467075X

Moshe Kelsen (D) https://orcid.org/0000-0002-4646-6725 


\section{References}

1. American Cancer Society Cancer Action Network. Barriers to patient enrollment in therapeutic clinical trials for cancer: a landscape report. https://www.fightcancer.org/ sites/default/files/National\%20Documents/ClinicalTrials-Landscape-Report.pdf (2018, accessed 4 March 2019).

2. Lara PN Jr, Higdon R, Lim N, et al. Prospective evaluation of cancer clinical trial accrual patterns: identifying potential barriers to enrollment. J Clin Oncol 2001; 19(6): 1728-1733.

3. Unger JM, Vaidya R, Hershman DL, et al. Systematic review and meta-analysis of the magnitude of structural, clinical, and physician and patient barriers to cancer clinical trial participation. J Natl Cancer Inst 2019; 111(3): 245-255.

4. Hallquist Viale P. Participation in cancer clinical trials: researching the causes of low accrual. J Adv Pract Oncol 2016; 7(2): 143-144.

5. Unger JM, Barlow WE, Martin DP, et al. Comparison of survival outcomes among cancer patients treated in and out of clinical trials. J Natl Cancer Inst 2014; 106(3): dju002.

6. Weber JS, Levit LA, Adamson PC, et al. American society of clinical oncology policy statement update: the critical role of phase I trials in cancer research and treatment. J Clin Oncol 2015; 33(3): 278-284.

7. Friedman MA and Cain DF. National Cancer Institute sponsored cooperative clinical trials. Cancer 1990; 65(10 Suppl): 2376-2382.

8. Durant RW, Wenzel JA, Scarinci IC, et al. Perspectives on barriers and facilitators to minority recruitment for clinical trials among cancer center leaders, investigators, research staff, and referring clinicians: enhancing minority participation in clinical trials (EMPaCT). Cancer 2014; 120(Suppl. 7): 1097-1105.

9. Mills EJ, Seely D, Rachlis B, et al. Barriers to participation in clinical trials of cancer: a meta-analysis and systematic review of patient-reported factors. Lancet Oncol 2006; 7(2): 141-148.

10. Piana R. The evolution of U.S. cooperative group trials: publicly funded cancer research at a crossroads, https:// www.ascopost.com/issues/march-15-2014/the-evolutionof-us-cooperative-group-trials-publicly-funded-cancerresearch-at-a-crossroads/ (2019, accessed 23 September 2019).

11. Kennedy-Martin T, Curtis S, Faries D, et al. A literature review on the representativeness of randomized controlled trial samples and implications for the external validity of trial results. Trials 2015; 16: 495.

12. Van Spall HG, Toren A, Kiss A, et al. Eligibility criteria of randomized controlled trials published in high-impact general medical journals: a systematic sampling review. JAMA 2007; 297(11): 1233-1240.

13. Kwiatkowski $\mathrm{K}$, Coe $\mathrm{K}$, Bailar JC, et al. Inclusion of minorities and women in cancer clinical trials, a decade later: have we improved. Cancer 2013; 119(16): 2956-2963.

14. Inclusion/exclusion criteria for National Cancer Institute (NCI) sponsored clinical trials: NCI and recommended protocol text guidance based on joint recommendations of the American Society of Clinical Oncology (ASCO) Friends of Cancer Research (Friends), https://ctep.cancer.gov/protocolDevelopment/docs/NCI_ASCO_Friends_Eligibility_Criteria.pdf (2018, accessed 23 September 2019).

15. Williams SL. Overcoming the barriers to recruitment of underrepresented minorities. Clin Res 2018; 32: 29-40.

16. Parra A, Karnad AB and Thompson IM. Hispanic accrual on randomized cancer clinical trials: a call to arms. J Clin Oncol 2014; 32(18): 1871-1873.

17. Hamel LM, Penner LA, Albrecht TL, et al. Barriers to clinical trial enrollment in racial and ethnic minority patients with cancer. Cancer Control 2016; 23(4): 327-337.

18. Wendler D, Kington R, Madans J, et al. Are racial and ethnic minorities less willing to participate in health research. PLoS Med 2006; 3(2): e19.

19. Comis RL, Miller JD, Aldige CR, et al. Public attitudes toward participation in cancer clinical trials. J Clin Oncol 2003; 21(5): 830-835.

20. Byrne MM, Tannenbaum SL, Gluck S, et al. Participation in cancer clinical trials: why are patients not participating? Med Decis Making 2014; 34: 116-126.

21. Meropol NJ, Buzaglo JS, Millard J, et al. Barriers to clinical trial participation as perceived by oncologists and patients. J Natl Compr Canc Netw 2007; 5(8): 655-664.

22. Heller C, Balls-Berry JE, Nery JD, et al. Strategies addressing barriers to clinical trial enrollment of underrepresented populations: a systematic review. Contemp Clin Trials 2014; 39(2): 169-182.

23. National Cancer Institute. National Cancer Institute Community Oncology Research Program: about NCORP, https://ncorp.cancer.gov/about/ (2018, accessed 9 February 2019).

24. Paskett ED, Katz ML, DeGraffinreid CR, et al. Participation in cancer trials: recruitment of underserved populations. Clin Adv Hematol Oncol 2003; 1(10): 607-613.

25. Boden-Albala B, Carman H, Southwick L, et al. Examining barriers and practices to recruitment and retention in stroke clinical trials. Stroke 2015; 46(8): 2232-2237.

26. Penberthy L, Brown R, Wilson-Genderson M, et al. Barriers to therapeutic clinical trials enrollment: differences between African-American and white cancer patients identified at the time of eligibility assessment. Clin Trials 2012; 9(6): 788-797.

27. Quinn GP, McIntyre J, Gonzalez LE, et al. Improving awareness of cancer clinical trials among Hispanic patients and families: audience segmentation decisions for a media intervention. J Health Commun 2013; 18(9): 1131-1147.

28. Cullen T. 16 reasons why people join clinical trials. Imperial Blog, 2015, imperialcrs.com

29. Chew LD, Bradley KA and Boyko EJ. Brief questions to identify patients with inadequate health literacy. Fam Med 2004; 36(8): 588-594.

30. IBM Corp. IBM SPSS statistics for windows, Version 24.0. Armonk, NY: IBM Corp, 2016.

31. Kornblith AB, Kemeny M, Peterson BL, et al. Survey of oncologists' perceptions of barriers to accrual of older 
patients with breast carcinoma to clinical trials. Cancer 2002; 95(5): 989-996.

32. Howerton MW, Gibbons MC, Baffi CR, et al. Provider roles in the recruitment of underrepresented populations to cancer clinical trials. Cancer 2007; 109(3): 465-476.

33. McCaskill-Stevens W, Pinto H, Marcus AC, et al. Recruiting minority cancer patients into cancer clinical trials: a pilot project involving the Eastern Cooperative Oncology Group and the National Medical Association. J Clin Oncol 1999; 17(3): 1029-1039.

34. St Germain D, Denicoff AM, Dimond EP, et al. Use of the national cancer institute community cancer centers program screening and accrual log to address cancer clinical trial accrual. J Oncol Pract 2014; 10(2): e73-e80.

35. Albrecht TL, Eggly SS, Gleason MEJ, et al. Influence of clinical communication on patients' decision making on participation in clinical trials. J Clin Oncol 2008; 26(16): 2666-2673.

36. Cherry K. Attitudes and behavior in psychology, https:// www.verywellmind.com/attitudes-how-they-form-changeshape-behavior-2795897 (2019, accessed 6 November 2019).

37. Meropol NJ, Wong YN, Albrecht T, et al. Randomized trial of a web-based intervention to address barriers to clinical trials. J Clin Oncol 2016; 34(5): 469-478. 